\title{
Heavy rainfall episodes in Ecuador during El Niño events and associated regional atmospheric circulation and SST patterns
}

\author{
A. Bendix and J. Bendix \\ Laboratory for Climatology and Remote Sensing, Faculty of Geography, Marburg, Germany \\ Received: 2 June 2005 - Revised: 14 October 2005 - Accepted: 18 October 2005 - Published: 9 January 2006
}

\begin{abstract}
To date very little is known about the relation between regional circulation patterns and sea surface temperature development in the Niño 1,2 region and the occurrence of heavy precipitation in Ecuador and northern Peru. The current study uses a comprehensive data set of 2544 Meteosat-3 imagery to investigate the dynamics of heavy precipitation during El Niño in 1991/92. Rainfall maps are retrieved by means of an adjusted version of the Convective Stratiform Technique (CST) and Cloud Motion Winds (CMW) are extracted from image sequences by using a special cross-correlation approach. A spatial factor analysis is applied to extract specific weather situations with heavy precipitation during El Niño events. The factor analysis yielded 16 factors. It has been proven that the factor patterns with the highest variance explanation also occur during the rainy season of non-El Niño years. However, 6 El Niño-specific situations could be derived which cause heavy rainfall, especially in coastal Ecuador and northern Peru. Multi-channel Sea Surface Temperatures (MCSST) and cloud motion winds are used to describe atmospheric and oceanic dynamics for these specific weather situations. The analysis shows that high SSTs in combination with strong SST gradients off the coast and warm SST bubbles lead to regional differences in moist instability and heavy rainfall. Both large scale circulation (reversal of the Walker cell) and regional dynamics (extended land-sea-breeze system) have been proven to contribute to El Niño rainfall.
\end{abstract}

\section{Introduction}

The coastal area of Ecuador is periodically affected by heavy precipitation during El Niño events which cause severe floods, damage of infrastructure, economical losses and an increase in the frequency of water-borne diseases (Gasparri et al., 1999; Bendix et al., 2003). Hence, the knowledge

Correspondence to: J. Bendix

(bendix@ staff.uni-marburg.de) of the spatio-temporal dynamics of heavy precipitation is of great importance for weather forecasting and the planning of disaster prevention measures. Over the last few years several studies on the spatial extension of rainfall anomalies during El Niño/La Niña events in Ecuador have been performed, mainly on a monthly basis (Bendix and Bendix, 1998; Rossel et al., 1998; Bendix, 1999; Bendix, 2000; Bendix et al., 2003). All studies showed that positive anomalies of rainfall during El Niño mainly affect the coastal plains of Ecuador to the western slopes of the Andes at altitudes $<1800$ ma.s.l. The increase in precipitation was found to be particularly high in central and southern Ecuador, with a peak time in February to March (Bendix and Bendix, 1998). This time of the year corresponds to the rainy season in non-El Niño years (Bendix and Lauer, 1992). The coastal area between central Ecuador and northern Peru (Sechura desert) has been proven to be the central El Niño area because the rainfall differences between normal years and El Niño events are particularly high (e.g. $>+2000 \%$ for the station Machala). Vuille et al. (2000) focussed on precipitation anomalies in the Andean region of Ecuador in relation to large-scale, El Niñolike circulation patterns and Pacific/Atlantic sea surface temperatures (SST).

Although it is stressed in literature that heavy rains in Ecuador during El Niño are frequently attributed to a reversal of the Walker circulation, Fig. 1 illustrates that appropriate large-scale circulation patterns such as indicated by a negative Southern Oscillation Index (SOI) are not necessarily a reliable predictor for coastal Ecuador. In general, positive rainfall anomalies in Guayaquil are related to a negative SOI during both normal (such as in 1991/92) and "super" events (such as in 1997/98). With respect to rainfall anomalies in Ecuador and northern Peru (Sechura), a normal event is characterised by a moderate increase in rainfall (e.g. $<+200 \%$ above the 30-year average for Guayaquil; $<+1000 \%$ for Talara). On the other hand, a super event reveals significantly higher anomalies, especially in the Sechura desert of northern Peru (e.g. $>+6000 \%$ for Talara; refer to Bendix 1999). However, phases of a negative SOI are not always associated 


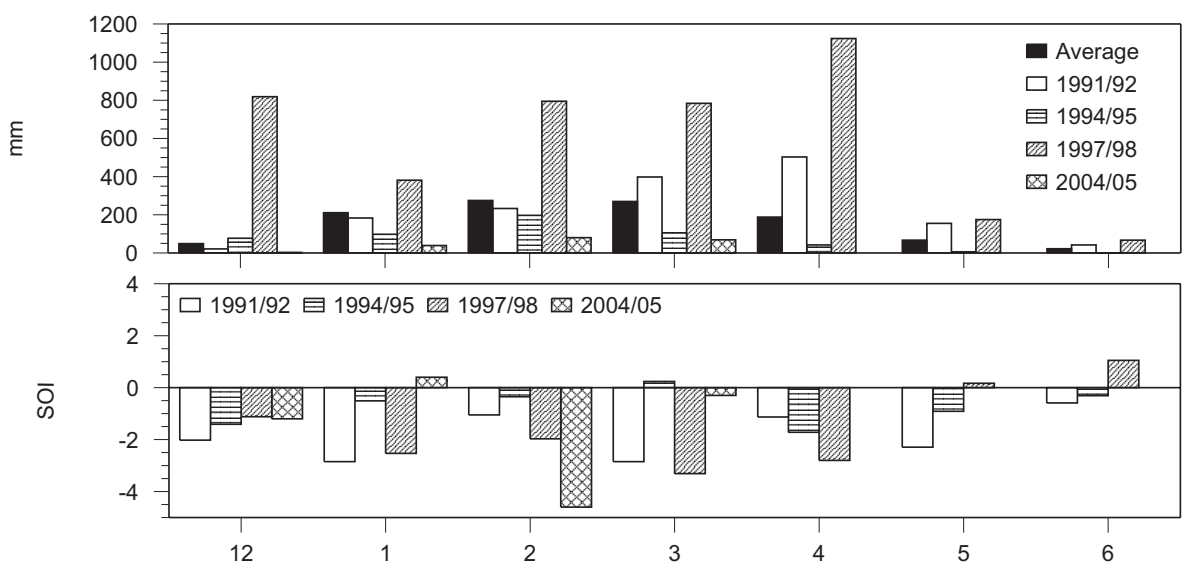

Fig. 1. Average monthly precipitation in Guayaquil during different phases of negative SOI (El Niño situation). Data: INAMHI, NOAA.

with positive rainfall anomalies in Ecuador and northern Peru. One example is the situation in 1994/95 which is classified as an El Niño year by Trenberth (1997) but rainfall in coastal Ecuador was clearly below average (Fig. 1). During this event, negative SOI values were caused by positive SST anomalies in the western and central Pacific (Niño-3,4 regions) which, however, did not reach the west coast of South America (Niño 1,2 region). The same applies to the latest events in 2002/03 (McPhaden, 2004) and 2004/05 (Fig. 1). Especially in February 2005, the SOI showed a dramatic decrease which was below the lowest monthly value since February 1983, the peak of the 1982-1983 El Niño. Despite the anomalously low monthly SOI, relatively weak positive SST anomalies suggested that the 2004-2005 warm event remained confined to the western and central parts of the equatorial Pacific. Consequently, rainfall in Guayaquil was significantly below average (Fig. 1). With respect to coastal Ecuador, therefore, a distinction must be made between El Niño events in the central Pacific (Niño 3,4 region) and eastern Pacific (Niño 1,2 region).

Bendix et al. (2000) could explain the high importance of regional SST patterns and mesoscale circulation in the eastern Pacific (Niño 1,2 region) on heavy rainfall formation in southern Ecuador and northern Peru during the 1991/92 and $1997 / 98$ events. However, to date, very little is known on the relation between regional SST/circulation pattern and weather type-specific spatio-temporal dynamics and the extension of heavy rains in Ecuador during east Pacific El Niño events. Hence, the major aim of the current study is to derive specific weather situations in the vicinity of the Niño 1,2 region with a unique spatio-temporal precipitation pattern by means of an event-based analysis of satellite data. The study area comprises the region from Galapagos (eastern boundary of the Niño 3 region) to the coast of Ecuador and northern Peru between $5^{\circ} \mathrm{N}$ and $15^{\circ} \mathrm{S}$.

\section{Data and methods}

The main data set for the current study is a series of 2,544 Meteosat-3 (IR 10.5-12.5 $\mu \mathrm{m}$ ) images with a half-hourly temporal resolution which covers 71 days of heavy precipitation during the El Niño 1991/92 in Ecuador. For the El Niño 1997/98, 11 days with maximum rainfall are investigated by means of GOES-8 (WV 6.47-7.02 $\mu \mathrm{m}$, IR 10.2$11.2 \mu \mathrm{m}$ ) and TRMM-PR data (product 2A25, refer to Iguchi et al., 2000). Ancillary data are radiosoundings from the stations Galapagos, Porto Velho, Manaus and Alta Floresta as well as a Digital Elevation Model (USGS GTOPO30).

The selection of days with heavy precipitation had the major goal of covering almost all days in the onset, mature and terminal phase of the El Niño event 1991/92 for Ecuador and northern Peru. The selection for the current study was based on the rainfall data $(7,13,19 \mathrm{LT})$ from 55 meteorological stations. A day was considered for further analysis if precipitation of at least one of the stations exceeded $48 \mathrm{~mm} \times 8 \mathrm{~h}^{-1}$ (for a definition refer to Heyer, 1972) and the precipitation event additionally exceeded $50 \%$ of the 30 -year monthly average. The second criterion was necessary because of the strong precipitation gradient from northern Ecuador to northern Peru, especially in the coastal plains.

The workflow of the current study is presented in Fig. 2. Satellite data are converted to daily rainfall maps by means of an adjusted version of the CST (Convective-Stratiform Technique) for Meteosat-3 (Adler and Negri, 1988; Bendix, 1997) and the Enhanced Convective Stratiform Technique (ECST) for GOES-8 (Reudenbach et al., 2001). Precipitation maps are computed for all single events of heavy precipitation (71 for EN 1991/92). The 1997/98 data are not included in the factor analysis but are used to check if the derived weather situations can also be observed during a "super" event.

Based on the 1991/92 data set, a spatial factor analysis is performed to extract maps of factor scores. The rainfall maps are summed up over a $10 \times 10$ pixel $(\sim 40 \times 40 \mathrm{~km})$ environment to exclude local effects during the factor analysis. The resulting factors characterise specific independent weather 


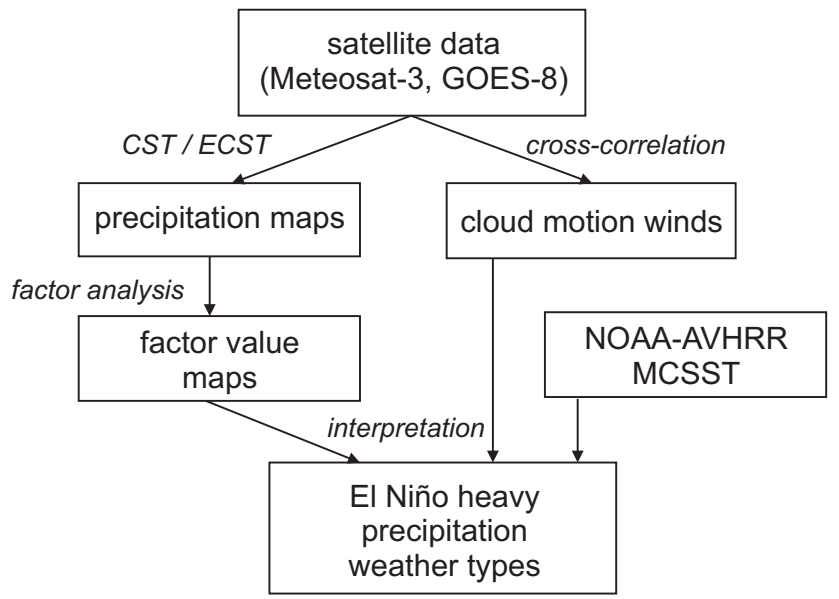

Fig. 2. Workflow of the current study.

situations for the formation of heavy precipitation during El Niño in the Niño 1,2 region. The advantage of a factor analysis in comparison to a cluster approach is the spatial (pixelwise) representation of the investigated variable (heavy precipitation) by the factor scores for a specific weather situation (factor). This allows for the distinction of specific spatial patterns of heavy precipitation representing different mechanisms of rainfall formation. Even if the factor scores are not an absolute measure of rainfall amount at a pixel location, they represent the rainfall tendency in every factor. In the present analysis, factor scores range between -3 and +8 . Negative factor scores indicate that within the factor the variable (in our case heavy precipitation) is below average, positive scores mean above average figures. It should be stressed that the data sets represent heavy precipitation, which means that below average can still mean rainfall above normal. Extremely high scores $(>+3)$ tend to occur in the dominant centres of heavy precipitation.

To link the specific situations of heavy rainfall as represented by the factors to dynamical mechanisms of rainfall formation, corresponding circulation and sea surface temperature (SST) patterns were computed additionally.

Circulation patterns were derived through the extraction of cloud motion winds (CMW) for three atmospheric levels (lower, mid and upper troposphere) from image sequences of Meteosat-3 and GOES-8. The computation is based on a moving cross-correlation technique (Schmetz et al., 1993; Bendix and Bendix, 1998) and was performed for every day with heavy precipitation. CMW maps were grouped by their membership to a specific factor and combined to a typical wind field in the lower and upper troposphere by consideration of the prevailing wind vectors.

Sea surface temperatures are examined by means of NOAA AVHRR-based weekly MCSST-data (Multichannel Sea Surface Temperatures; refer to McClain et al., 1985). Single MCSST maps are assigned to the relevant factor and a weighted average is calculated.
Table 1. Results of factor analysis for El Niño 1991/92.

\begin{tabular}{ccc}
\hline Factor No. & Explained variance [\%] & No. of rainfall events \\
\hline 1 & 17 & 18 \\
2 & 8 & 10 \\
3 & 4 & 7 \\
4 & 4 & 7 \\
5 & 3.7 & 4 \\
6 & 3.3 & 4 \\
7 & 3 & 4 \\
8 & 2.6 & 4 \\
9 & 2.3 & 1 \\
10 & 1.9 & 2 \\
11 & 1.9 & 2 \\
12 & 1.8 & 2 \\
13 & 1.8 & 2 \\
14 & 1.6 & 2 \\
15 & 1.5 & 1 \\
16 & 1.4 & 1 \\
$\Sigma$ & 59.8 & 71 \\
\hline
\end{tabular}

\section{Results of the factor analysis}

Table 1 shows the results of the factor analysis. 16 independent weather situations could be extracted which explain $\sim 60 \%$ of the variance in the data set.

The first two factors contribute nearly half of the explained variance. The map of factor scores for factor 1 is presented in Fig. 3 which indicates rainfall in the coastal parts of Ecuador.

The Amazon region shows well-developed precipitation areas close to the borders between Brazil, Peru and Colombia. The average circulation situation for this factor based on CMW data reveals an upper air divergence over the area of high factor scores, and well-developed upper level easterlies which pass the Andes over the Ecuador region. It is striking that low level trades originating in the south $\mathrm{Pa}$ cific anticyclone are present along the coast of Peru and the Niño 1,2 region, which can be suppressed by the reversal of the Walker circulation as observed for several Niños in the past (EN 1972/73; Wyrtki, 1975). The north-westerly upper-level stream-flow over the Niño 1,2 region points to a well-developed Hadley component along the Peruvian coast. Also average sea surface temperatures illustrate only moderate positive anomalies off the coast of Ecuador for this factor (Fig. 5). The situation is comparable for factor 2 (not shown here) where both the zonal (upper-level easterlies) and the meridional stream-flow (low-level trades, upper-level north-westerlies) are intensified. A comparison with the atmospheric dynamics during non-El Niño years as described, for example, by Kreuels et al. (1975) and Bendix and Lauer (1992) reveals that the same weather situation is characteristic during the normal rainy season. Hence, heavy precipitation during El Niño in the study area (factor 1-3) can originate from weather patterns which are also relevant in nonEl Niño years. However, even the moderate positive SST 


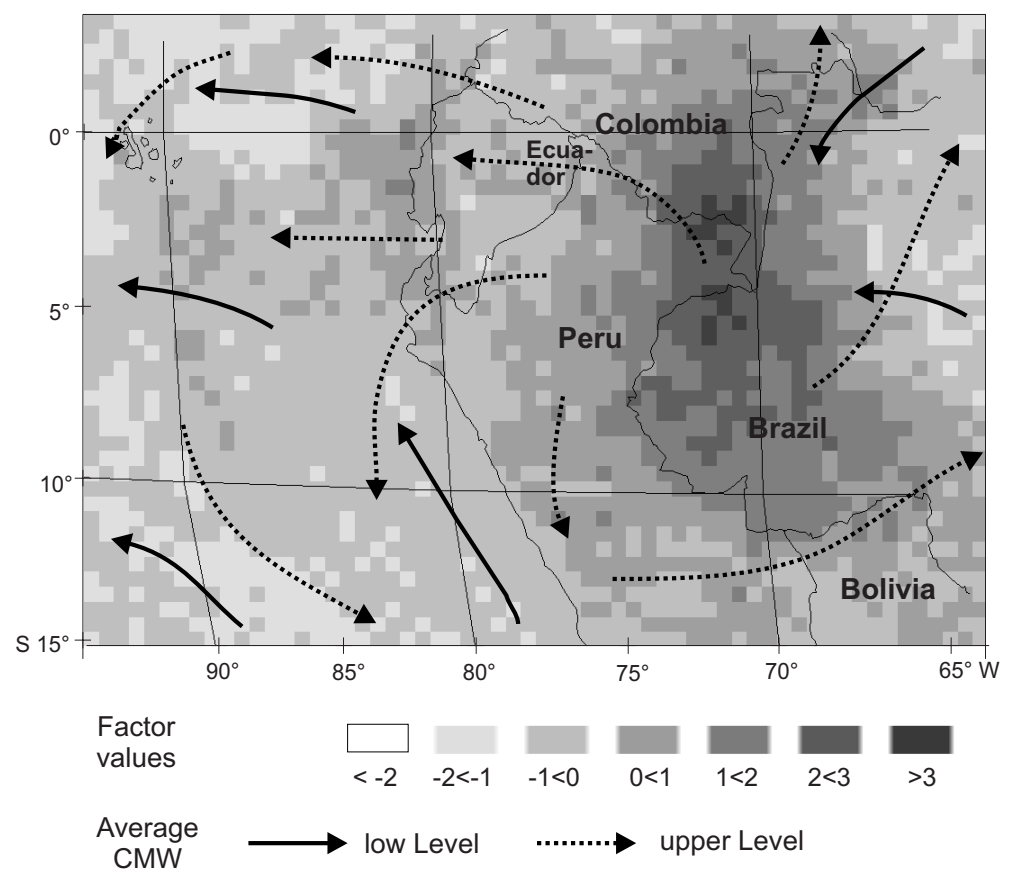

Fig. 3. Factor scores and average CMW fields for factor 1.

anomalies off the coast cause an intensification of precipitation in the study area during El Niño.

In comparison to normal atmospheric dynamics, all other factor maps show specific deviations from average circulation, SST and rainfall pattern. Hence, they are classified as specific El Niño weather situations. Because of the large spatial extent of the study area used for calculating the factors (Niño 1,2 region and adjacent Andean and Amazon region), the factor analysis also extracts factors which seem to have the severest rainfall outside the coastal plains of Ecuador and northern Peru. Factor 3 (not shown), for instance, reveals the strong effect of the Bolivian Anticyclone at the northern Altiplano, but shows an interrupted rain field in the Ecuadorian coastal region. Single case studies of the rain events which had their highest loadings to factor 3 showed that spatial and temporal isolated rainfalls with precipitation amounts of $>100 \mathrm{~mm}$ characterised the weather situations. However, most of the factors have their highest factor values placed in the Niño 1,2 region. Especially the factors 5, 7, 8, 9, 10, 11, $12,13,14$ and 16 show extraordinary rainfall in the coastal plains of Ecuador and northern Peru and their adjacent areas. Figure 4 presents some of the typical El Niño weather situations of the factors 8-11, 13 and 16 .

The corresponding weighted averages of SST are illustrated in Fig. 5. The factors explain $11 \%$ of the total variance but contribute most significantly to accumulated rainfall. Factors 8 and 11 are representative for heavy precipitation ranging from the coastal lowlands of northern and central Ecuador to the north Peruvian Sechura. Factors 9 and 16 are linked to heavy precipitation in southern coastal Ecuador and the Sechura desert, factor 10 points to a local increase of heavy precipitation in the Gulf of Guayaquil area and fac- tor 13 indicates extremely intensified rainfall activity at the western and eastern Andean slopes from the Colombian border to northern Peru.

CMW circulation patterns and SST can help to explain the spatial extension of precipitation. During situations characterised by factor 8 , atmospheric circulation is generally weak. Low level trades close to the Peruvian coast are not established and the upper-level easterlies from the Amazon region are weak. Heavy precipitation develops off the coast of central Ecuador where strong SST gradients are visible which are the basis for moist atmospheric instability. Similar rainfall patterns are observed for factor 11 but are related to a typical El Niño circulation pattern. Westerly wind anomalies are indicated by low level CMWs in the Niño 1,2 region between the equator and $10^{\circ} \mathrm{S}$ and are countered by well developed upper-level easterlies. Hence, this factor is a clear example of a reversal of the Walker circulation. Factor 9 shows a southward shift of the main rain area to southern coastal Ecuador and northern Peru. While the circulation patterns are weak (as for factor 8), a warm water bubble off the Peruvian coast, surrounded at its northern and eastern edges by a cold water tongue originating in the off-shore area of the Sechura coast, causes strong regional SST gradients. In this case, moist instability is the most likely reason for the origin of heavy rains (see also Lau et al., 1997; Bony et al., 1997; Tompkins and Craig, 1999; Tompkins, 2001). A similar SST configuration of factor 16 leads to a comparable rainfall situation. Factor 10 seems to be mainly the consequence of limited-area SST development. Heavy precipitation especially occurs in the Gulf of Guayaquil and surrounding coastal areas. While the wind field is generally weak, a warm water tongue along the southern Columbian coast extends to the Gulf area and leads 


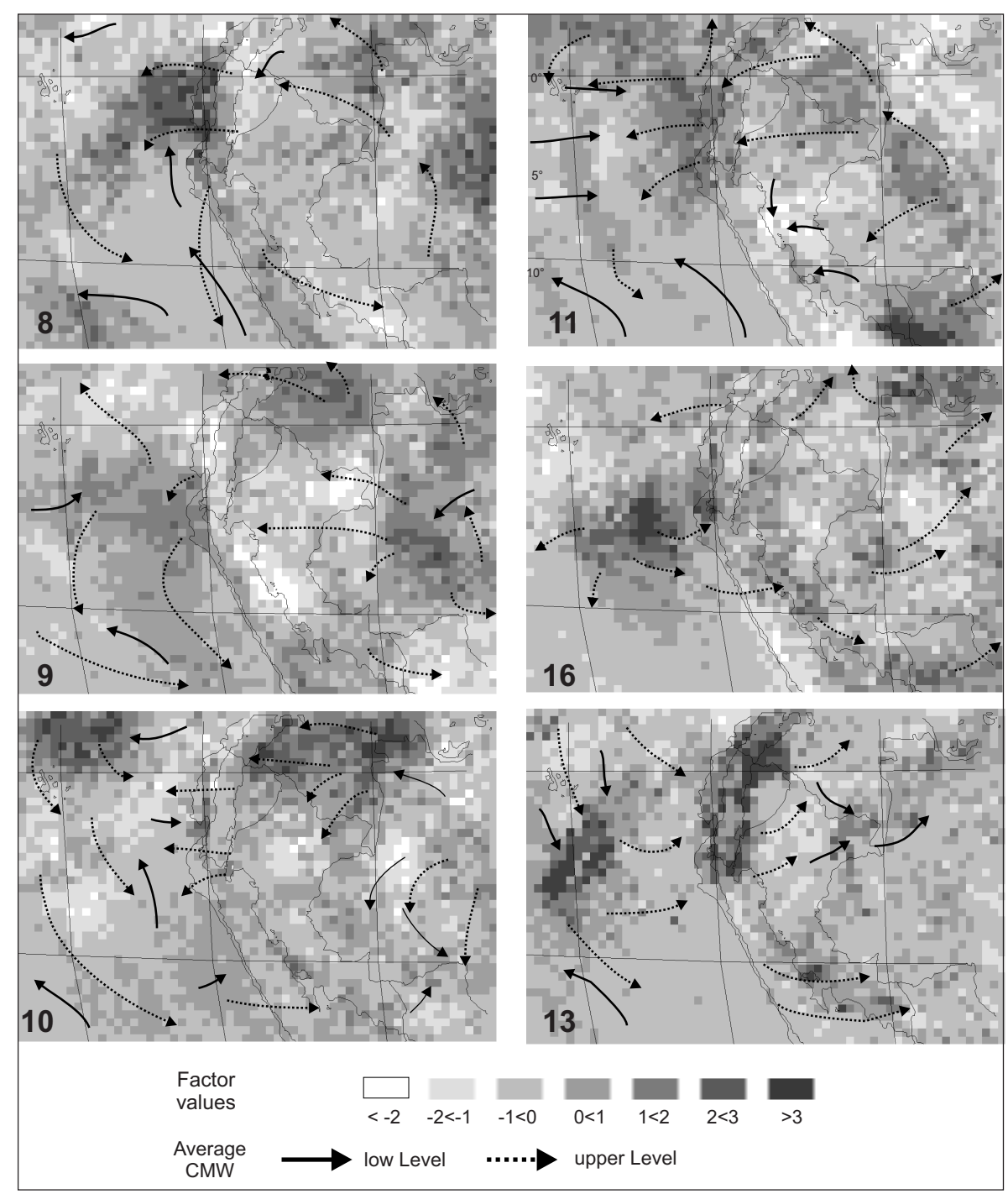

Fig. 4. Factor scores and average CMW fields for factors which cause heavy precipitation in the central Niño area of Ecuador and northern Peru.

to moist instability. The limited low-level westerly streamflow in front of the Gulf is most likely not related to a reversal of the Walker cell but could indicate an intensified land-sea-breeze phenomenon which has been proven to be important for rainfall formation during normal and "super" El Niño events (refer to Schütte, 1968; Fett and Tag, 1983; Caviedes and Endlicher, 1989; Bendix, 2000; Bendix et al., 2000). However, this sub-scale phenomenon cannot be investigated properly with the spatial resolution of the current study. A very intensive situation is indicated by factor 13 . Average SST patterns reveal the highest SSTs close to the zone of the highest factor scores above the Pacific. CMW circulation points to strong equatorial westerly wind anomalies which are still clearly developed in the upper troposphere. Low level circulation seems to be weak. Moist instability, the strong westerly wind anomaly leads to deep convection which occurs in the coastal areas of Ecuador and northern Peru as well as the western and eastern Andean slopes. A similar situation is also observed for the $1997 / 98$ El Niño (16 March 1998; refer to Bendix et al., 2003).

\section{Conclusions}

The current study has shown that satellite data exploitation in combination with factor analysis is a useful tool for the determination of specific El Niño weather situations leading to heavy precipitation in the central El Niño area of Ecuador and northern Peru. However, the factor analysis explained only $60 \%$ of the total variance. Previous investigations (e.g. Horel and Cornejo-Garrido, 1986; Goldberg et al., 1987; Bendix, 2000) have shown that also mesoscale (multi-convective complexes) and local effects like the landsea-breeze and up-slope-breeze phenomena can boost the formation of heavy precipitation, especially if coastline configuration favours convergent flow as could be observed for 

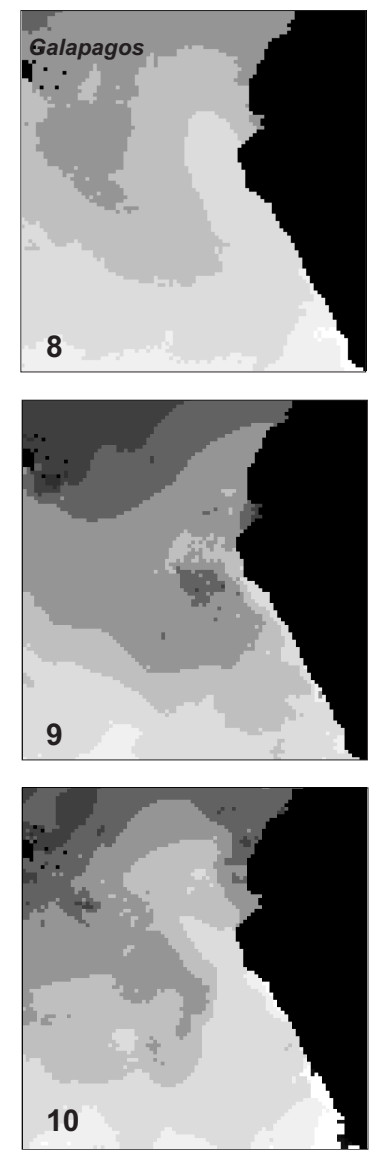
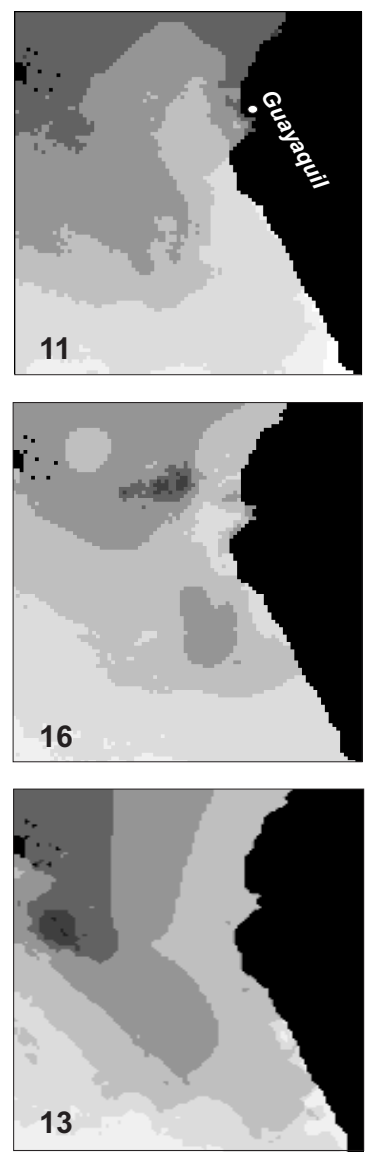
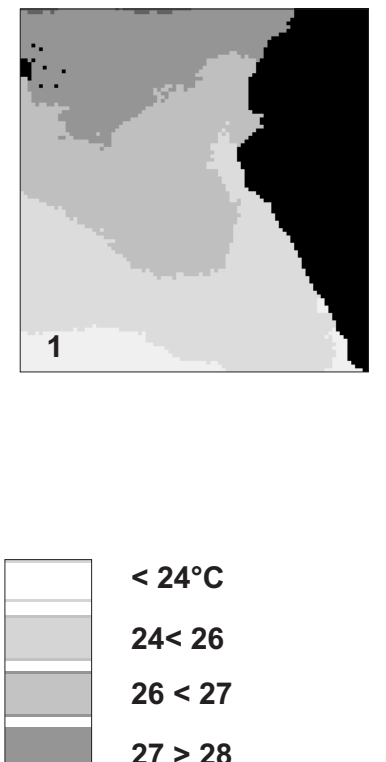

$<24^{\circ} \mathrm{C}$

$24<26$

$26<27$

$27>28$

$28<29$

$>=29$

land

Fig. 5. Average MCSST for the factor maps of Figs. 3 and 4.

the nocturnal land-breeze system in the Gulf of Guayaquil (Bendix, 2000). The local phenomena are not properly represented by the current factor analysis due to the spatial aggregation of rainfall maps. Hence, subscale processes are most likely responsible for the unexplained variance. Future studies must focus on a full resolution factor analysis for the central El Niño area of Ecuador and northern Peru in order to provide a more detailed view on mesoscale and local weather modification during El Niño.

Acknowledgements. The El Niño Precipitation Experiment (ENPEX) project was generously funded by the German Research Council DFG (Be 1780/1-1, 1-2). The authors would like to thank Enrique Palacios (INAMHI) for providing the meteorological data from Guayaquil.

Edited by: P. Fabian and J. L. Santos

Reviewed by: two anonymous referees

\section{References}

Adler, R. F. and Negri, A. J.: A satellite infrared technique to estimate tropical convective and stratiform rainfall, J. Appl. Meteor., 27, 30-51, 1988.

Bendix, J. and Lauer, W.: The rainy seasons in Ecuador and their climatic interpretation (in German), Erdkunde, 46, 118-134, 1992.

Bendix, J.: Adjustment of the Convective-Stratiform Technique (CST) to estimate 1991/93 El Niño rainfall distribution in Ecuador and Peru by means of Meteosat-3 IR data, Int. J. Remote Sensing, 18, 1387-1394 and 2707, 1997.

Bendix, J. and Bendix, A.: Climatological Aspects of the 1991/92 El Niño in Ecuador, Bulletin de L'Institut Francaise d'Etudes Andines, 27, 655-666, 1998.

Bendix, J.: A comparative analysis of the major El Niño events in Ecuador and Peru over the last two decades, Zbl. Geol. Paläontol I, H. 7/8, 1119-1131, 1999.

Bendix, J.: Precipitation dynamics in Ecuador and Northern Peru during the 1991/92 El Niño - A Remote Sensing perspective, Int. J. Remote Sensing, 21, 533-548, 2000.

Bendix, J., Bendix, A., and Richter, M.: El Niño 1997/98 in northern Peru: An indication for a change of the ecoystem? (in German), Peterm. Geogr. Mit., 144, H. 4, 20-31, 2000.

Bendix, J., Gämmerler, S., Reudenbach, C., and Bendix, A.: A case study on rainfall formation during El Niño 1997/98 in Ecuador and surrounding areas as inferred from GOES-8 and TRMM-PR 
observations, Erdkunde, 57, 81-93, 2003.

Bony, S., Lau. K.-M., and Sud, Y. C.: Sea surface temperature and large-scale circulation influences on tropical greenhouse effect and cloud radiative forcing, J. Clim., 10, 2055-2076, 1997.

Caviedes, C. N. and Endlicher, W.: Die Niederschlagsverhältnisse in Nordperu während des El Niño-Southern OscillationEreignisses von 1983, Die Erde, 129, 81-97, 1989.

Fett, R. W. and Tag, P. M.: Satellite Observation and Numerical Model Results of Sea Breeze Effects as Applied to the West Coast of South America, First International Conference on Southern Hemisphere Meteorology, 31.7.-6.8.1983, Sao Jose dos Campos, Brazil, American Met. Soc., Boston, 337-340, 1983.

Gasparri, E., Tassara, C., and Velasco, M.: El fenómeno de El Niño 1997-1999 en El Ecuador, Del desastre a la prevención, Ediciones Abya Yala, Quito, Ecuador, 1999.

Goldberg, R. A., Tisnado, M. G., and Scofield, R. A.: Characteristics of extreme rainfall events in northwestern Peru during the 1982-83 El Niño period, J. Geophys. Res., 92, 14 225-14241, 1987.

Heyer, E.: Witterung und Klima, Teubner Verlagsgesellschaft, Leipzig, 1972.

Horel, J. D. and Cornejo-Garrido, A. G.: Convection along the coast of northern Peru during 1983: Spatial and temporal variations of clouds and rainfall, Month. Wea. Rev., 114, 2091-2105, 1986.

Iguchi, T., Kozu, T., Meneghini, R., Awaka, J., and Okamoto, K.: Rainfall-profiling algorithm for the TRMM Precipitation Radar, J. Appl. Meteor., 39, 2038-2052, 2000.

Lau, K.-M., Wu, H.-T., and Bony, S.: The role of large-scale atmospheric circulation in the relationship between tropical convection and sea surface temperatures, J. Clim., 10, 381-392, 1997.

Kreuels, R., Fraedrich, K., and Ruprecht, E.: An aerological climatology of South America, Meteor. Rdsch., 28, 17-24, 1975.
McClain, E. P., Pichel, W. G., and Walton, C. C.: Comparative performance of AVHRR-based multichannel sea-surface temperatures, J. Geophys. Res., 90, 11 587-11 601, 1985.

McPhaden, M. J.: Evolution of the 2002/03 El Niño, Bul. Am. Meteor. Soc., 85, 677-695, 2004.

Reudenbach, C., Heinemann, G., Heuel, E., Bendix, J., and Winiger, M.: Investigation of summertime convective rainfall in Western Europe based on a synergy of remote sensing data and numerical models, Meteor. Atmos. Phys., 76, 23-41, 2001.

Rossel, F., Mejía, R., Ontaneda, G., Pombosa, R., Roura, J., Le Goulven, P., Cadier, E., and Calvez, R.: Regionalization of El Niño influence on rainfall in Ecuador, Bulletin de L'Institut Francaise d'Etudes Andines, 27, 643-654, 1998.

Schmetz, J., Holmlund, K., Hoffmann, J., Strauss, B., Mason, B., Gaertner, V., Koch, A., and van de Berg, L.: Operational cloud motion winds from Meteosat infrared images, J. Appl. Meteor., 32, 1206-1225, 1993.

Schütte, K.: Untersuchungen zur Meteorologie und Klimatologie des El Niño-Phänomens in Ecuador und Nordperu, Bonner Met. Abh., 9, Bonn, 1968.

Trenberth, K. E.: The Definition of El Niño, Bul. Am. Meteor. Soc. 78, 2771-2777, 1997.

Tompkins, A. M. and Craig, G. C.: Radiative-convective equilibrium in a three-dimensional cloud ensemble models, Quart. J. Roy. Met. Soc., 124, 2073-2097, 1999.

Tompkins, A. M.: On the Relationship between tropical convection and sea surface temperature, J. Climate, 14, 633-637, 2001.

Vuille, M., Bradley, R. S., and Keimig, E.: Climate variability in the Andes of Ecuador and its relation to tropical Pacific and Atlantic sea surface temperature anomalies, J. Clim., 13, 2520 2535, 2000.

Wyrtki, K.: El Niño - The dynamic response of the equatorial Pacific ocean to atmospheric forcing, J. Phys. Oceanogr., 5, 572584, 1975. 